\title{
Unusually high plasma values of many tumour markers in a patient with idiopathic pulmonary fibrosis
}

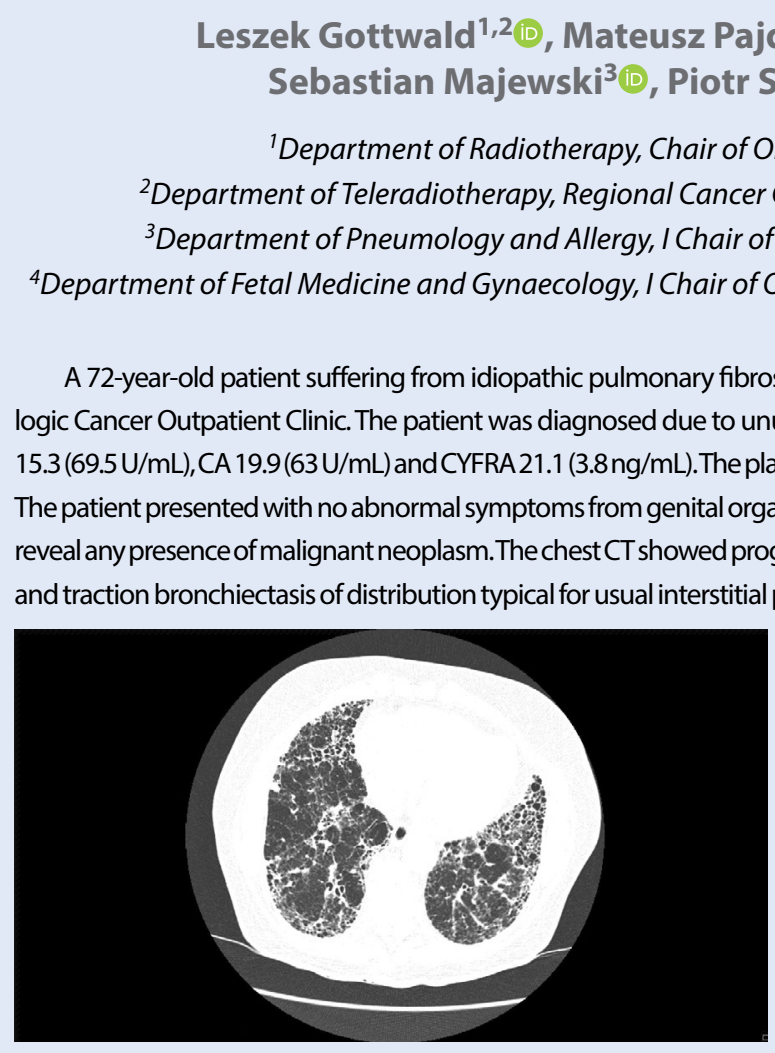

Figure 1. High-resolution computed tomography scan of the IPF

\section{of} ris was also documented by lung function tests which showed loss of forced vital capacity of $310 \mathrm{~mL}$ ( $11 \%$ drop of predicted value) in the period of 12 months. CT scans did not reveal any radiological symptoms of malignancy. After a four-week and three month follow-up, plasma levels of previously elevated markers were tested again and the results were similar to the previous ones: CA125 (253 U/mL and $258 \mathrm{U} / \mathrm{mL})$, HE4(208 pmol/Land 206 pmol/L),CA15.3(67.2U/mLand69.5U/mL),CA $19.9(54.1 \mathrm{U} / \mathrm{mL}$ and $66.5 \mathrm{U} / \mathrm{mL})$, CYFRA $21.1(3.8 \mathrm{ng} / \mathrm{mL}$ and $4.3 \mathrm{ng} / \mathrm{mL})$, CEA $(2.37 \mathrm{ng} / \mathrm{mL}$ and $2.83 \mathrm{ng} / \mathrm{mL})$ and SCCAg $(1.4 \mathrm{ng} / \mathrm{mL}$ and $1.8 \mathrm{ng} / \mathrm{mL})$. After a oneyear follow-up, further progression of IPF without symptoms of neoplastic disease is observed.

The IPF is defined as a disease of unknown origin which springs from interstitial pneumonia. It leads to a chronic, irreversible fibrosing of the lungs. The process of fibrosis does not occur in other tissues and is limited to the lungs. High resolution computed tomography is the recommended imaging technique to make the diagnosis. Clinical symptoms are nonspecific and unusually high plasma values of some tumor markers e.g. CA125 can be seen, which can lead to suspicion of adnexal cancer [1, 2].

Gynaecologic patients presenting elevated plasma levels of CA125 and HE4 only if adnexal cancer is excluded other reasons for high levels of these markers can be considered. The role of modern imaging techniques in patients with IPF, especially computed tomography in the differentiation between progression of pulmonary fibrosis and adnexal cancer, is crucial and the value of serum tumour markers assessment is limited. If no adnexal tumour is diagnosed careful follow-up is required.

In our patient the progression of IPF, an extremely rare condition in gynaecologic practice, was the reason for the elevated plasma levels of the CA125, HE4, CA19.9, CA15.3 and CYFRA 21.1. It is known, that the tumour markers CA125, CA19.9, CA15.3 and CYFRA 21.1 can accurately characterize severity of the IPF [3-5]. A review of the English literature in Medline base by searching the items idiopathic pulmonary fibrosis and HE4 showed no one items. Our case is the first report describing the relationship between the IPF and HE4.

\section{REFERENCES}

1. Martinez FJ, Collard HR, Pardo A, et al. Idiopathic pulmonary fibrosis. Nat Rev Dis Primers. 2017; 3: 17074, doi: 10.1038/nrdp.2017.74, indexed in Pubmed: 29052582.

2. Raghu G, Remy-Jardin M, Myers JL, et al. American Thoracic Society, European Respiratory Society, Japanese Respiratory Society, and Latin American Thoracic Society. Diagnosis of Idiopathic Pulmonary Fibrosis. An Official ATS/ERS/JRS/ALAT Clinical Practice Guideline. Am J Respir Crit Care Med. 2018; 198(5): 44-68, doi: 10.1164/rccm.201807-1255ST, indexed in Pubmed: 30168753.

3. Fujita J, Obayashi Y, Yamadori I, et al. Marked elevation of CA19-9 in a patient with idiopathic pulmonary fibrosis: CA19-9 as a bad prognostic

Corresponding author:

Leszek Gottwald

Department of Radiotherapy, Chair of Oncology, Medical University of Lodz, Poland; Department of Teleradiotherapy, Regional Cancer Centre, Copernicus Memorial Hospital of Lodz 4 Paderewskiego St, 93-509 Lodz, Poland; e-mail: leszek.gottwald@umed.lodz.pl factor. Respirology. 1998; 3(3): 211-214, doi: 10.1111/j.1440-1843.1998. tb00124.x, indexed in Pubmed: 9767623.

4. Maher TM, Oballa E, Simpson JK, et al. An epithelial biomarker signature for idiopathic pulmonary fibrosis: an analysis from the multicentre PROFILE cohort study. Lancet Respir Med. 2017; 5(12): 946-955, doi: 10.1016/S2213-2600(17)30430-7, indexed in Pubmed: 29150411.

5. Rusanov V, Kramer MR, Raviv Y, et al. The significance of elevated tumor markers among patients with idiopathic pulmonary fibrosis before and after lung transplantation. Chest. 2012; 141(4): 1047-1054, doi: 10.1378/chest.11-0284, indexed in Pubmed: 21940773. 